\title{
UM OLHAR JOVEM SOBRE A ESCOLA DE ENSINO MÉDIO: VIVENCIAR E SIGNIFICAR
}

\author{
Carolina Moraes Fuzaro ${ }^{1}$ \\ José Edson da Silva ${ }^{2}$ \\ Glaucia Rodrigues da Costa Carvalho ${ }^{3}$ \\ Márcia Maria Dias Reis Pacheco ${ }^{4}$
}

\begin{abstract}
Resumo: Este artigo contribui para a discussão da relação dos jovens com a escola de Ensino Médio da rede pública. Apresenta parte de uma pesquisa de natureza básica e descreve os sentidos atribuídos à escola e suas relações com o mundo do trabalho contemporâneo. Dentro de uma abordagem qualitativa, foi feito um estudo de caso em uma escola de Ensino Médio da rede pública do estado de São Paulo. A coleta de dados foi feita em 2015 através de questionários. Os dados foram analisados pelo conjunto de técnicas da Análise de Conteúdo à luz da perspectiva teórica histórico-cultural. O texto faz uma apresentação da condição do Ensino Médio no Brasil e dos sentidos que os jovens pesquisados atribuem a esse nível de ensino. A guisa de conclusão, observa-se um sentido de preparação para o futuro, de escola como instituição responsável pela formação profissional ainda que esteja passando por crises de identidade e desafios de ordem social, econômico e político.
\end{abstract}

Palavras-chave: Escola de Ensino Médio; Jovens; Mercado de trabalho.

\footnotetext{
1 Universidade de Taubaté, Brasil. E-mail: smcaroli@yahoo.com.br.

2 Universidade de Taubaté, Brasil. E-mail: joseedson853@gmail.com.

3 Universidade de Taubaté, Brasil. E-mail: glaucia@personnaconsulting.com.br.

${ }^{4}$ Universidade de Taubaté, Brasil. E-mail: marreis@gmail.com.
} 